\title{
Correction to: Numerical simulation of non-uniform roughness distribution on compressor performance
}

\author{
Haiou Sun ${ }^{1} \cdot$ Meng Wang $^{1} \cdot$ Zhongyi Wang $^{1} \cdot$ Jingyuan $^{\text {Ma }}{ }^{1}$
}

Published online: 6 March 2018

(c) JASNAOE 2018

\section{Correction to: J Mar Sci Technol} https://doi.org/10.1007/s00773-017-0483-5

In the original publication there were some corrections to be updated.

The updated version is provided in this correction article.

The sentence in the fourth paragraph of the Chap. 3, "In this study, average roughness parameter was used.", should be read as "In this study, average roughness parameter was used [24-26]."

In addition, the following three references should be added at the end of the references section.

24. Morini M, Pinelli M, Spina PR, Venturini M (2011) Numerical analysis of the effects of nonuniform surface

roughness on compressor stage performance. J Eng Gas Turbines Power 133(7):072402-072402-8

25. Morini M, Pinelli M, Spina PR, Venturini M (2010) Computational fluid dynamics simulation of fouling on axial compressor stages. J Eng Gas Turbines Power 132(7):072401-072401-10

26. Aldi N, Morini M, Pinelli M, Spina PR, Suman A, Venturini M (2013) Performance evaluation of nonuniformly fouled axial compressor stages by means of computational fluid dynamics analyses. J Turbomach 136(2):021016-021016-11

The original article can be found online at https://doi.org/10.1007/ s00773-017-0483-5.

Zhongyi Wang

b205030024@126.com

1 College of Power and Energy Engineering, Harbin

Engineering University, Harbin 150001, China 